\title{
The Effect of Nickel on Shaping the Structure of Al-Cu-Mn Alloys
}

\author{
Marcin Górnya , Gabriela Sikora ${ }^{a *}$, Edward Tyrała ${ }^{\mathrm{a}}$, Paweł Repeća

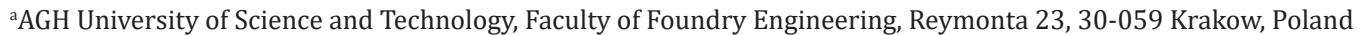 \\ *e-mail: gsikora@agh.edu.pl
}

Received: 22 November 2016/Accepted: 5 January 2017/Published online: 17 March 2017

This article is published with open access at AGH University of Science and Technology Press

\begin{abstract}
This study investigated the effect of nickel on shaping the structure of aluminum alloys of the Al-Cu-Mn type in the "as-cast" condition and after heat treatment according to the T6 procedure. The aluminum alloys of type $\mathrm{Al}-5 \% \mathrm{Cu}-1 \% \mathrm{Mn}$, containing nickel in a range of up to $1.9 \%$, were taken into consideration in this work. Experiments were carried out for thin-walled thickness casting $(\mathrm{g}=5 \mathrm{~mm}$ ) and for reference casting with a wall thickness of $\mathrm{g}=35 \mathrm{~mm}$. Metallographic investigations of both the macro- and micro-structure were conducted to estimate the secondary dendrite arm spacing (SDAS), average diameter (dav) of the primary a (Al) grains, and surface fraction of the interdendritic phases (f). Moreover, the degree of dissolution of these interdendritic phases during the solution treatment process was determined. An SEM-EDS analysis was conducted, from which it follows that the addition of nickel at the level of $0.5 \%$ changes the un-dissolved particles from a needle-like $\beta$-Fe shape to blocky and coagulated. Higher additions of nickel starting from $0.88 \%$ ) give rise to as many as four phases with higher copper content, the deficit of which results in the smaller strengthening effect of $\alpha$ (Al) dendrites.
\end{abstract}

\section{Keywords:}

Al-Cu-Mn alloys, cooling curves, primary $\alpha(\mathrm{Al})$ grains, SDAS, T6 heat treatment

\section{INTRODUCTION}

Aluminum-copper alloys are important engineering materials used in applications that require high tensile properties. These alloys are extensively in use for high-quality castings in industrial applications, such as automotive and airplane parts [1, 2]. The mechanical properties of $\mathrm{Al}-\mathrm{Cu}$ alloys can be improved using various metallurgical parameters, including melt treatments, heat treatments, and alloying element additions [3]. The final quality of castings depends on the structure of the alloy; i.e., the number of primary grains of $\alpha(\mathrm{Al})$ dendrites [4], their shape, the types of phases located in the interdendritic regions $[5,6]$, and any defects - especially shrinkage porosity [7].

It is well known that the content of alloying elements has a significant impact on the size and shape of the primary grains of $\alpha(\mathrm{Al})$ dendrites and even on the transformation from columnar to equiaxed crystallization (exogenous - endogenous) [8-12].Smallsecondary dendrite arm spacing (SDAS) and less dendrite branching leads to a more-homogeneous structure.

It is well known that nickel in aluminum alloys is commonly used along with copper to enhance mechanical properties at an elevated temperature [13, 14]. An aluminum-nickel system exhibits a eutectic reaction at $5.7 \%$ wt., and the solubility of nickel in aluminum is limited to $0.05 \%$ wt. [15]. This very-limited solubility does not significantly contribute to matrix strengthening [16]. In the presence of copper, nickel forms compounds such as $\mathrm{Al}_{6} \mathrm{Cu}_{3} \mathrm{Ni}$ or $\mathrm{Al}_{3}(\mathrm{Ni}, \mathrm{Cu})_{2}$. These are some of the most-thermally-stable, exerting a positive influence upon mechanical properties at elevated temperatures. However, the formation of these compounds is accompanied by a reduction of copper concentration in an $\alpha(\mathrm{Al})$ matrix and, correspondingly, to lower strength at room temperature [15]. Increasing the Ni content results in a small reduction in the thermal expansion coefficient $[14,17]$. In the literature, there are publications examining the effects of nickel on the structure and mechanical properties of aluminum alloys in various systems [13, 18-20]. However, there is no quantitative data on the effect of the addition of nickel on the following: (a) the number of primary $\alpha(\mathrm{Al})$ grains; (b) values of SDAS (Secondary dendrite arm spacing); (c) concentration limits of alloying elements or impurities for which $\mathrm{Al}-\mathrm{Cu}-\mathrm{Ni}$ phases are formed; and (d) a strengthening effect after heat treatment of aluminum alloys in the $\mathrm{Al}-\mathrm{Cu}-\mathrm{Mn}$ system. In this connection, the aim of this work is to study the effect of nickel on shaping the structure of the $\mathrm{Al}-\mathrm{Cu}-\mathrm{Mn}$ alloy in "as-cast" and T6 heat-treatment conditions.

\section{EXPERIMENTAL PROCEDURE}

Within the framework of this study, six Al-5Cu alloys were studied. The experimental melts were prepared in 
a medium-frequency induction furnace with a 5-kg-capacity aluminum. The furnace charge consisted of the following charge materials: primary aluminum (purity: 99.85\%), AlCu50, AlNi20, and AlMn75.

After the charge was melted, this liquid metal was overheated up to $750^{\circ} \mathrm{C}$, and then the ingots were cast with a variable amount of nickel. The liquid metal was cast into dried molds made of a fine, traditional molding sand with bentonite of standard Y-shaped type ingots (according to ASTM A536-84) with a wall thickness of $5 \mathrm{~mm}$ in the bottom part. The pouring temperature was set at $750^{\circ} \mathrm{C}$.

The results of the chemical composition analysis of the studied alloys carried out using a SPECTRAMAXx emission spectrometer with spark excitation are shown in Table 1.

Table 1

Results of chemical composition analyses

\begin{tabular}{cccccccc}
\hline \multirow{2}{*}{$\begin{array}{c}\text { Alloys } \\
\text { no. }\end{array}$} & \multicolumn{7}{c}{ Element, \% wt. } \\
\cline { 2 - 8 } & $\mathrm{Si}$ & $\mathrm{Fe}$ & $\mathrm{Cu}$ & $\mathrm{Mn}$ & $\mathrm{Ti}$ & $\mathrm{Ni}$ & $\mathrm{Al}$ \\
\hline $\mathrm{A}$ & 0.20 & 0.13 & 4.96 & 0.84 & 0.013 & - & Bal. \\
\hline $\mathrm{B}$ & 0.23 & 0.14 & 4.91 & 0.85 & 0.017 & 0.48 & Bal. \\
\hline $\mathrm{C}$ & 0.20 & 0.12 & 4.95 & 0.83 & 0.014 & 0.88 & Bal. \\
\hline $\mathrm{D}$ & 0.21 & 0.13 & 4.93 & 0.85 & 0.017 & 1.23 & Bal. \\
\hline E & 0.23 & 0.13 & 5.01 & 0.83 & 0.013 & 1.66 & Bal. \\
\hline F & 0.15 & 0.12 & 4.93 & 0.81 & 0.014 & 1.90 & Bal. \\
\hline
\end{tabular}

The records of cooling curves were performed in the reference castings (standard quick cup with a wall thickness of $35 \mathrm{~mm}$ ) with the use of thermoelements of type K (NiCr-NiAl). An Agilent 34970A multi-channel electronic module was used to record temperature with a time step of $0.5 \mathrm{~s}$.

Samples for metallographic examinations were taken from the bottom part of the ingots $(\mathrm{g}=5 \mathrm{~mm})$. The samples were also heat treated (T6), which included solution treatment for 16 hours at $540^{\circ} \mathrm{C}$, quenching in water, and artificial aging for 3 hours at $250^{\circ} \mathrm{C}$.

The samples were grinded, polished, and electrolytically etched using Barker's reagent. During the etching, an electric current at $30 \mathrm{~V}$ was fed for a minimum time of 1 min in accordance with the ASTM E407-07 Standard. The metallographic examinations were performed using an optical microscope (Leica MEF4M) and stereomicroscope (MZ6) using polarized light.

The SDAS parameter, average diameter of primary grain (dav) of phase $\alpha(\mathrm{Al})$, and area fraction of interdendritic phases (f) were performed by using an automatic image analyzer (Image $1.49 \mathrm{~h}$ ).

Microanalysis of the chemical composition was performed using a scanning electron microscope (Jeol $5500 \mathrm{LV}$ ) equipped with an EDS System.

Brinell hardness tests were performed using an HPO-250 universal machine with a $2.5 \mathrm{~mm}$ diameter steel ball and $612.9 \mathrm{~N}$ load according to the $\mathrm{PN}-\mathrm{H}-$ 04350:1991 Standard.

\section{RESULTS AND THEIR ANALYSES}

\subsection{Thermal analysis}

Figure 1 shows the recorded cooling and crystallization curves in the reference castings of selected alloys $\mathrm{A}, \mathrm{C}$, and $\mathrm{E}$.

a)
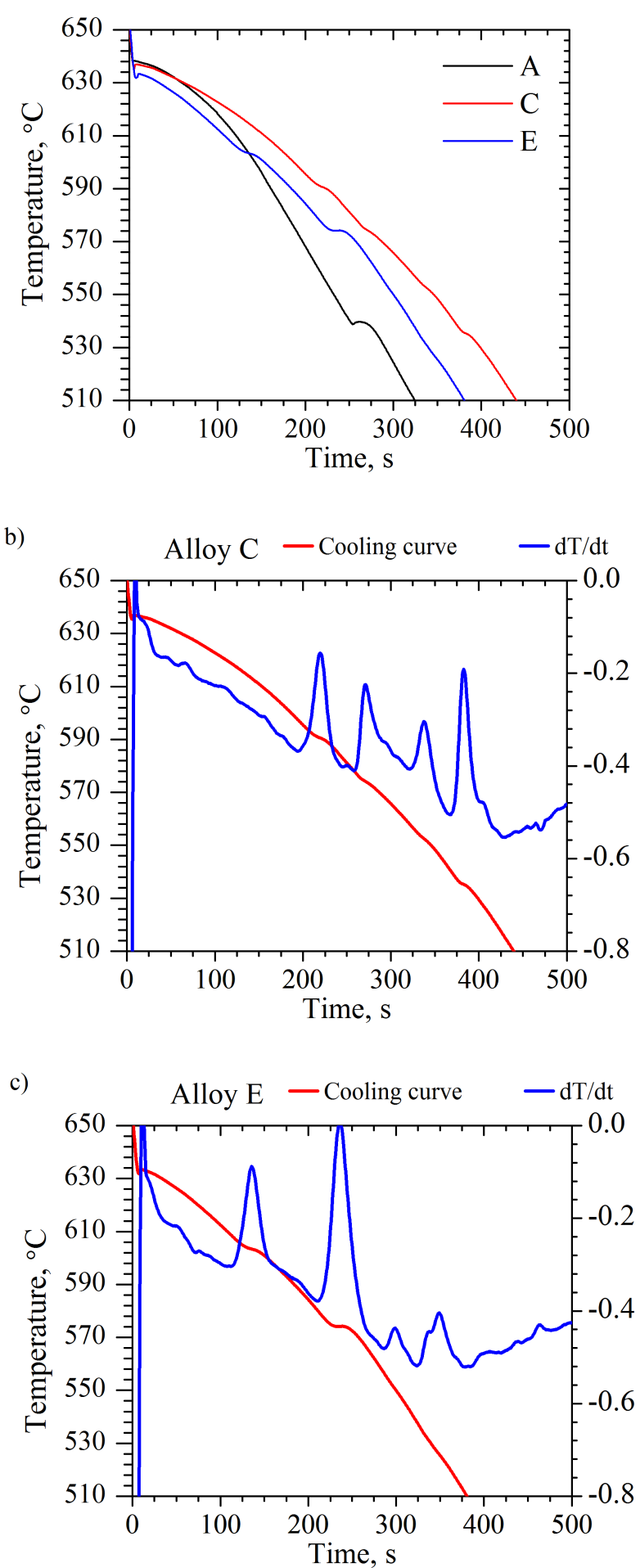

Fig. 1. Cooling curves and their first derivatives from alloys $A, C$, and E: (a) cooling curves recorded in the whole range; (b) and (c) in the transformation of interdendritic phases region 
On the basis of these cooling curves, a thermal analysis was performed by determining the characteristic points of the transformations (which are summarized in Table 2).

Table 2

Results of thermal analysis

\begin{tabular}{ccccccc}
\hline \multirow{2}{*}{ Alloy no. } & \multirow{2}{*}{$\mathrm{TB},{ }^{\circ} \mathrm{C}$} & \multirow{2}{*}{$\Delta \mathrm{T},{ }^{\circ} \mathrm{C}$} & \multicolumn{4}{c}{$\mathrm{T}_{\text {min- } \mathrm{E}}{ }^{\circ} \mathrm{C}$} \\
\cline { 4 - 7 } & & & $\mathrm{E} 1$ & $\mathrm{E} 2$ & $\mathrm{E} 3$ & $\mathrm{E} 4$ \\
\hline $\mathrm{A}$ & 646 & 122.6 & - & - & - & 538.8 \\
\hline $\mathrm{C}$ & 646 & 130.7 & 591.3 & 574.3 & 553.5 & 535.6 \\
\hline $\mathrm{E}$ & 646 & 134.4 & 603.7 & 574.1 & 553.5 & 527.7 \\
\hline
\end{tabular}

where:

TB - temperature at the beginning of the crystallization process; $\mathrm{T}_{\min -\mathrm{E}}-$ minimal temperature at the beginning of interdendritic phase crystallization;

$\Delta \mathrm{T}$ - the difference between temperature at the beginning of the crystallization process and solidus temperature.

The cooling curves for reference alloys C and E (i.e., containing nickel) have more stops (from E1 to E4) as compared to base alloy A. This shows the crystallization of different phases and heat generation, the effect of which is visible on the derivative curves of temperature vs. time.

It is worth noting that the temperature of the transformations from E1 to E4 are different, which proves the influence of nickel on the range of transformation (eutectic or peritectic) temperatures. From Figure 1 and the data shown in Table 2, it follows that nickel significantly lowers the transformation temperature of E4, which increases the crystallization temperature range in the tested alloys. One should also pay attention to the time of each transformation E1-E4 (Figs. 1b, 1c), a determinant of which may be the first derivative curve. Their course is proportional to the phases' fractions, which are created at different stages during solidification. In addition to that from Figure 1c, it follows that there is a high „intensity” of thermal effects during E1 and E2 transformations in alloy $\mathrm{E}$ as compared to those in alloy $\mathrm{C}$.

\subsection{Macro- and micro-structure}

Figures 2 and 3 show the micro- and macro-structures in the reference and thin-walled castings, respectively.
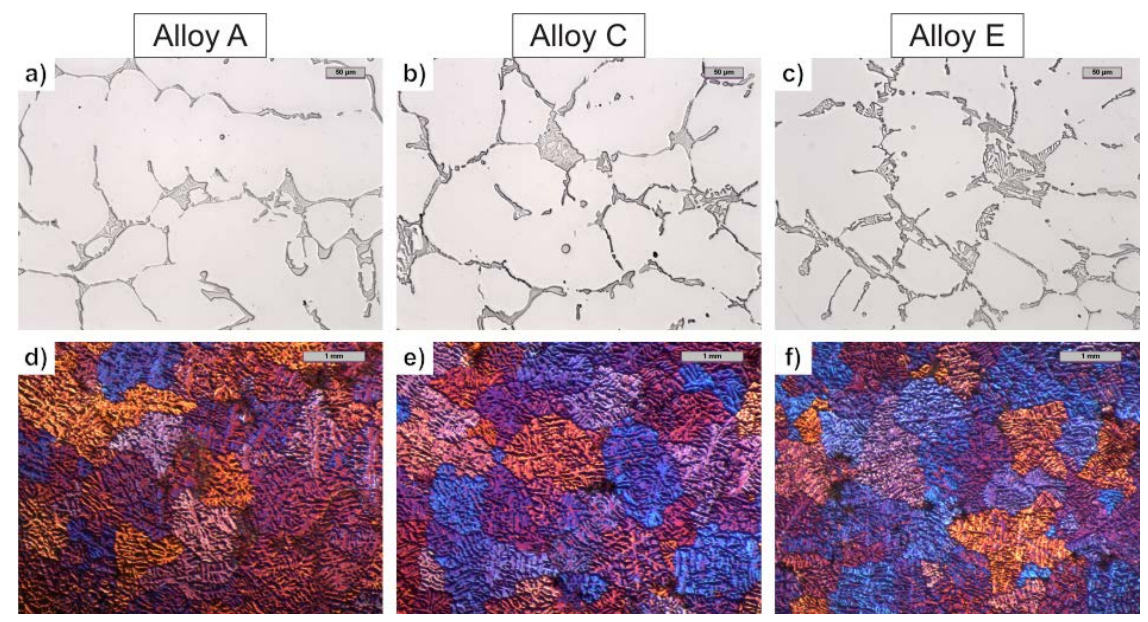

Fig. 2. Microstructures (a, b, c) and macrostructures (d, e, f) of alloys A, C, and E in the reference castings; polished surface (200x mag.) and etched (10x mag.)
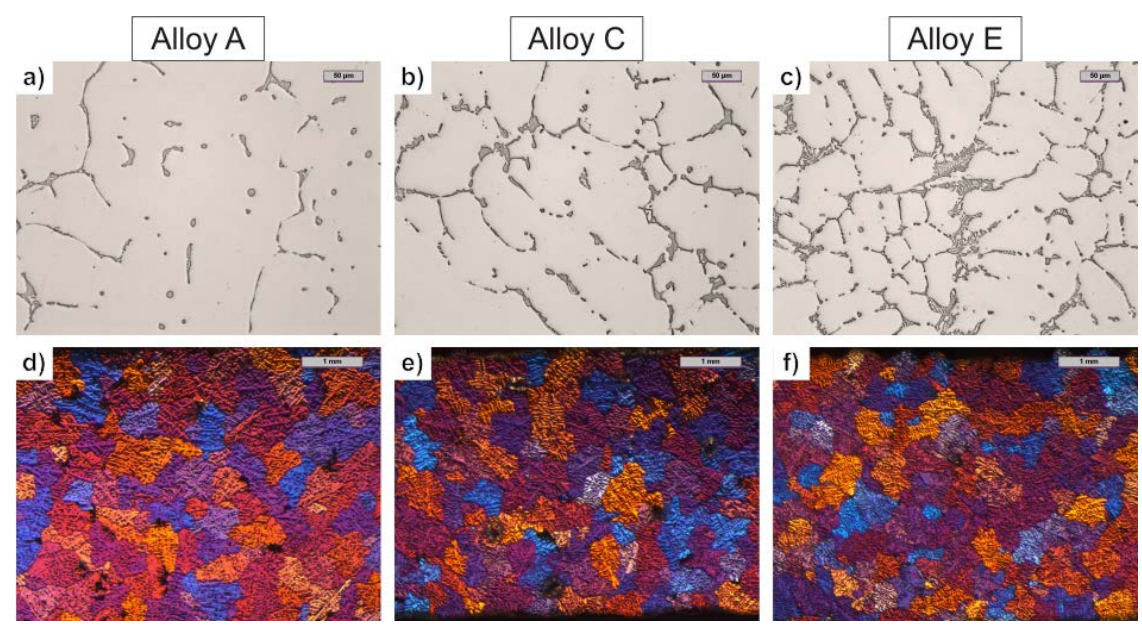

Fig. 3. Microstructures (a, b, c) and macrostructures (d, e, f) of alloys A, C, and E in the reference castings; polished surface (200x mag.) and etched (10x mag.) 
In Figure 4, the results of metallographic examinations ie., the average diameter dav of primary $\alpha(\mathrm{Al})$ grains (a) and SDAS parameter (b) as a function of the nickel content in the castings, are shown.

a)

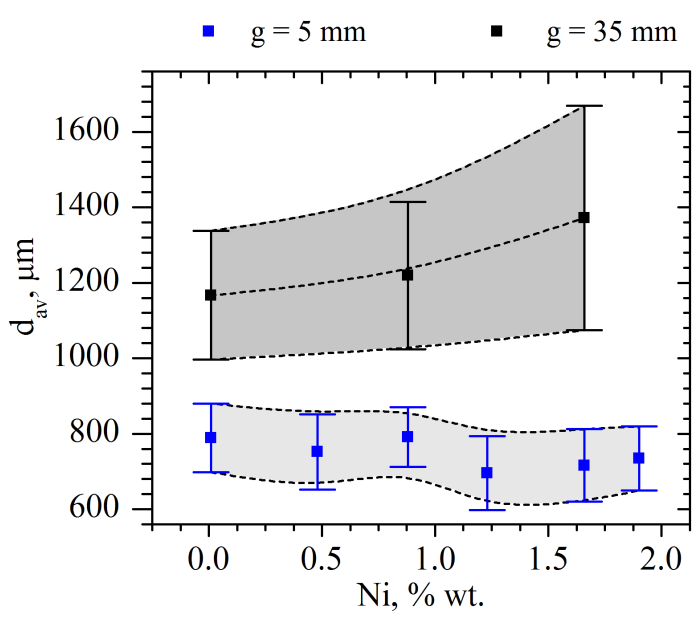

b)

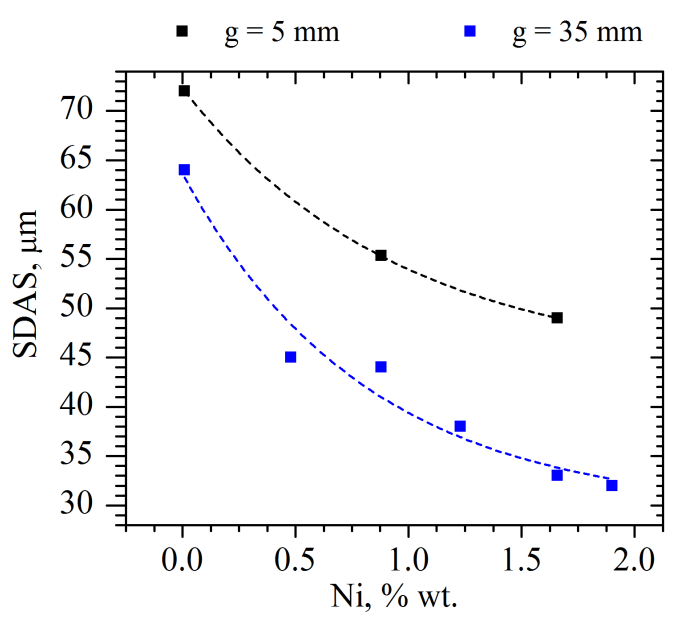

Fig. 4. The average diameter of primary $\alpha(\mathrm{Al})$ grains (a) and SDAS parameter (b) as a function of nickel content in the Al-Cu-Mn alloysF (c) after heat treatment

Analysis of the macrostructures indicate that, in the investigated alloys, equiaxed dendrites of the $\alpha(\mathrm{Al})$ phase were obtained. From Figure 4, it follows that the smallest dimension of the primary grain $(1167 \pm 170 \mu \mathrm{m})$ was attained in the base Alloy A (without nickel). In the alloy with nickel content at a level $0.88 \%$ wt. (Alloy C), the dimension of the grains of $\alpha(\mathrm{Al})$ dendrites is equal to $1219 \pm 195 \mu \mathrm{m}$, whereas the dimension of the primary grain in Alloy E reached $1372 \pm 297 \mu \mathrm{m}$. In the investigated range of $\mathrm{Ni}$ content, the differences in grain dimensions in the reference castings are small when compared to the uncertainty in the measurements (see Fig. 4a). From the macrostructure analysis, it follows that the addition of nickel causes changes in the shape of the primary grains in the reference castings. This is particularly visible in the case of the alloy with high nickel content at a level of $1.9 \%$ wt. (Alloy E). In this case, the biggest dimension of the primary grains was attained, but with the highest uncertainty of measurements, which is caused by the change in shape of the grains. In the case of the thin-walled castings, there is no significant change in grain size or its morphology with increased nickel content. The measurement of the SDAS parameter indicates that there is a significant decrease of its value with increased nickel content in the investigated $\mathrm{Al}-\mathrm{Cu}-\mathrm{Mn}$ alloys. These changes are observed in both the thin-walled and reference castings. The effect of reducing the SDAS parameter with an increased addition of alloying elements in aluminum alloys is widely observed [9]. In the present $\mathrm{Al}-\mathrm{Cu}-\mathrm{Mn}$ system, the addition of nickel is segregated into a liquid phase. The higher the Ni concentration, the faster the liquid metal reaches crystallization of the interdendritic phases. Distribution of the alloying elements (segregation) is a slow diffusion process, which causes a reduction in the primary grain growth of dendrites and, therefore, a decrease in the SDAS parameter. In the investigated $\mathrm{Al}-\mathrm{Cu}-\mathrm{Mn}$ system, nickel reduces the growth rate and changes the shape (in the reference castings) of the primary grains through segregation.

Figure 5 shows the change in the microstructures of alloys A, B, and F after heat treatment (T6). The addition of nickel caused a change in the shape of the interdendritic phases that were not affected by T6 heat treatment. The transformation from plate-like phases (faceted-crystal) to fragmented and coagulated particles (non faceted-crystal) was observed. The increase in the amount of nickel caused an increase in the area fraction of these $\mathrm{Ni}$-rich interdendritic phases in the microstructure.
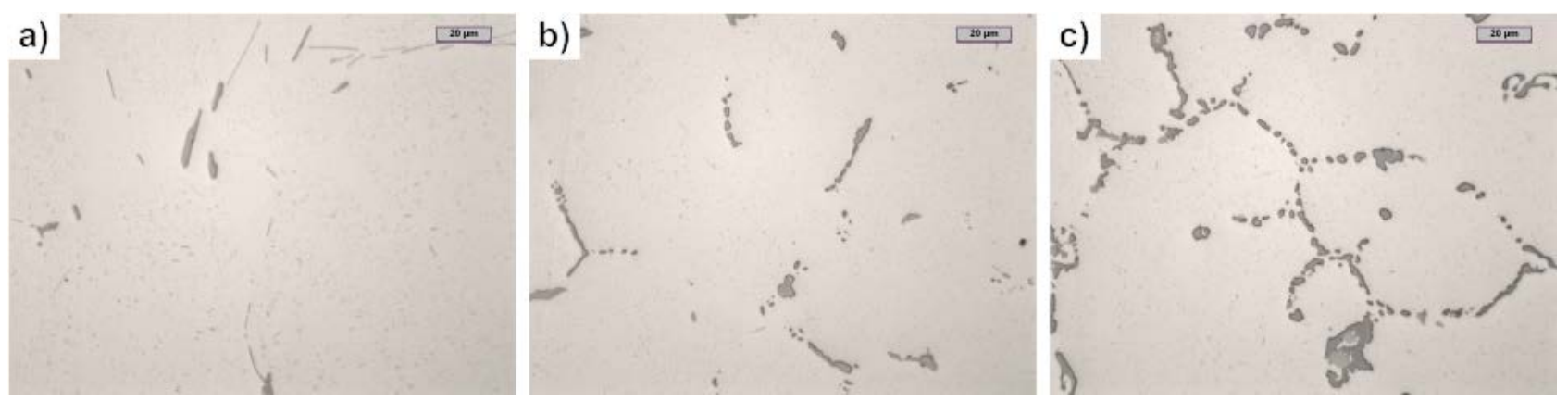

Fig. 5. Microstructure of thin-walled castings after T6 heat treatment: (a) alloy A, (b) alloy B, and (c) alloy F; mag. 500x, polished surface 
Changes in the area fraction of the interdendritic phases in the microstructure of the $\mathrm{Al}-\mathrm{Cu}-\mathrm{Mn}$ alloy in "as-cast" condition and after T6 heat treatment are shown in Figure 6a.

To determine the degree of solubility of the above-mentioned interdendritic phases during their solution treatment, a relative loss (UE) was calculated according to the following equation:

$$
U_{E}=100 \times\left(1-\frac{f_{T 6}}{f_{F}}\right), \%
$$

where:

$$
\begin{aligned}
& f_{T 6}-\quad \text { area faction of interdendritic phases } \\
& \text { after T6 heat treatment, \%; } \\
& f_{F}-\quad \begin{array}{l}
\text { area faction of interdendritic phases } \\
\text { in "as-cast" conditions, } \% .
\end{array}
\end{aligned}
$$

The results of measurement of the relative loss (UE) as a function of nickel content in the $\mathrm{Al}-\mathrm{Cu}-\mathrm{Mn}$ alloys are shown in Figure 6b.

The metallographic examinations indicate the significant role of nickel in the shaping of the interdendritic phases in $\mathrm{Al}-\mathrm{Cu}-\mathrm{Mn}$ alloys. The rise in the amount of nickel causes an increase in the area fraction of the interdendritic phases in both "as-cast" and after-heat-treatment conditions. From Figure 6a, it follows that heat treatment

a)

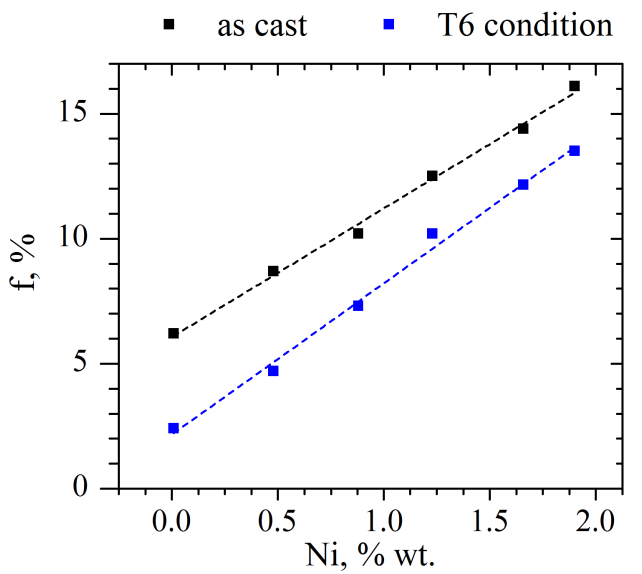

does not affect the occurrence of these phases; their relevant loss (UE) decreased from 61 to $17 \%$ for alloy A and F, respectively (see Fig. 6b).

From Fig. 6a, it is seen that, in alloy $\mathrm{F}$ (the highest addition of nickel $-1.9 \% \mathrm{wt}$.), the area fraction of the interdendritic phases after heat treatment reaches 13\%, which is close to the value (16\%) attained in "as-cast" conditions.

\subsection{Microanalysis of chemical composition EDS}

Figure 7 shows the microstructures of alloys after heat treatment (T6) of the highlighted spots from an EDS microanalysis of the chemical composition.

An EDS analysis revealed that, in the base alloy A in "as-cast" conditions, the $\mathrm{Cu}$ content in the metallic matrix is at a level of $2.7 \%$ wt. T6 heat treatment caused an increase in $\mathrm{Cu}$ content in the dendrites (the total copper contents as dissolved in the $\alpha(\mathrm{Al})$ phase and in the reinforced particles) up to $5 \%$ wt. (alloy A after T6 heat treatment).

The addition of $\mathrm{Ni}$ in the amount of $1.66 \% \mathrm{wt}$. (alloy $\mathrm{E}$ - "as-cast") caused a decrease in the $\mathrm{Cu}$ content in the metallic matrix to the level of $1.3-1.5 \%$ wt. Heat treatment of the aluminum alloys with nickel additions (alloys B and F) caused an increase in the $\mathrm{Cu}$ content in the dendritic phases to the levels of $3.8-4.0 \%$ wt. and $2.4-2.9 \% \mathrm{wt}$., respectively.

b)

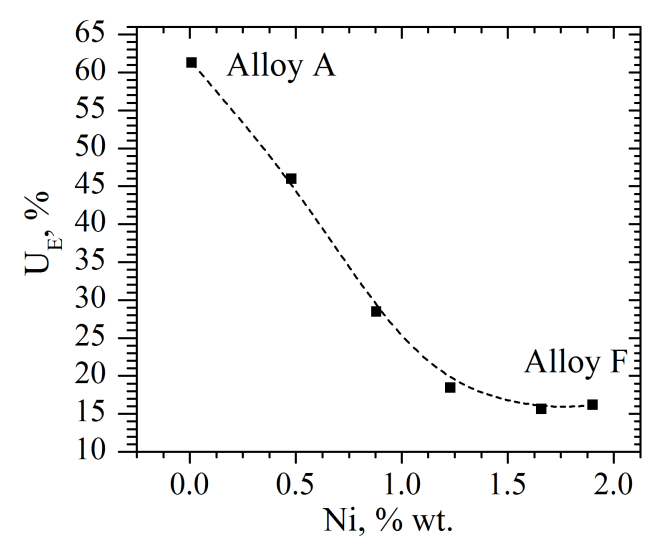

Fig. 6. Area fraction of interdendritic phases in "as-cast" condition and after T6 heat treatment: (a) and the relative loss of interdendritic phases after heat treatment; (b) as a function of nickel content in the Al-Cu-Mn alloys
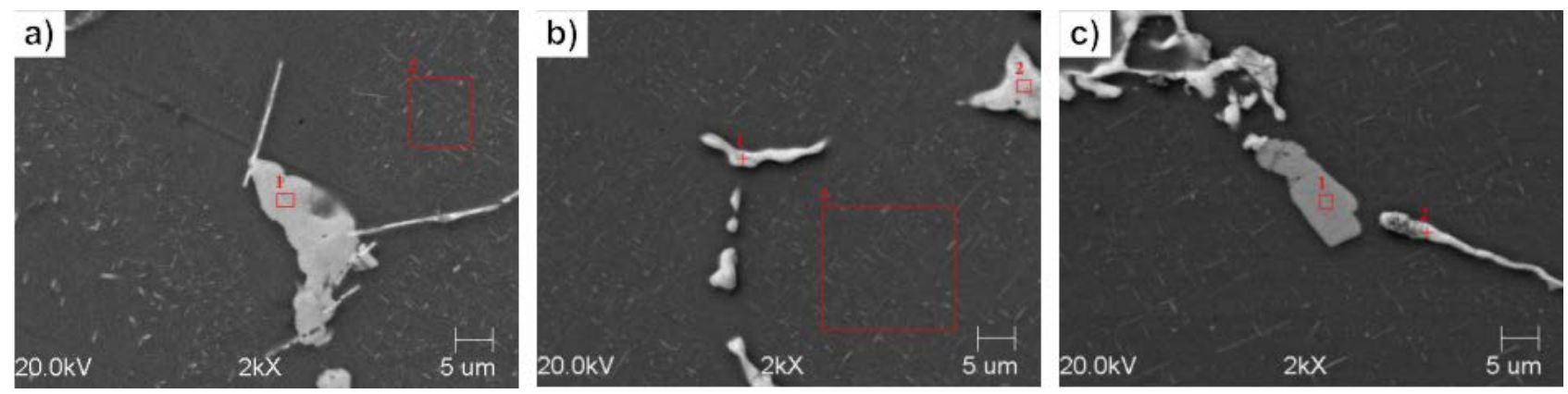

Fig. 7. SEM microstructure of investigated alloys A (a), B (b), and F (c) after heat treatment 
An SEM analysis allowed us to estimate the dimensions and linear density (number of particles per unit length) of the reinforced particles in alloys $A, B$, and $F$. The graphic presentation of these results is shown in Figure 8.

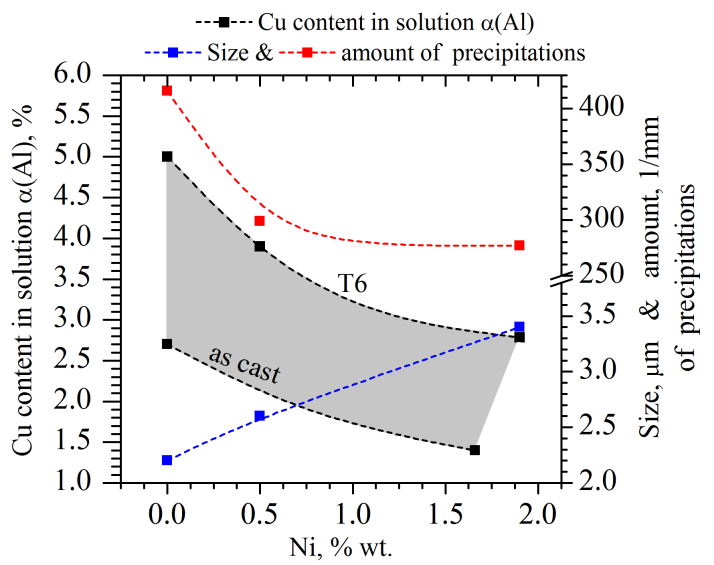

Fig. 8. The results of stereological measurements of reinforced particles and $\mathrm{Cu}$ content in solid solution of $\alpha(\mathrm{Al})$ aluminum as a function of nickel content

An analysis of the results shown in Figure 8 indicates that, as nickel content increases, there is a significant decrease in the number of reinforced particles and, simultaneously, an increase in their dimensions. Consequently, nickel decreases the strengthening effect of the metallic matrix.

An EDS analysis revealed the significant influence of nickel on the formation of different nickel-rich phases in the interdendritic areas. It is worth mentioning here that, after $\mathrm{T} 6$ heat treatment, the $\mathrm{Al}_{2} \mathrm{Cu}$ phase is not visible in the interdendritic areas of alloy $\mathrm{A}$, which proves that the heat-treatment process was properly conducted. In the aforementioned interdendritic areas, the needlelike and irregular phases that were unaffected by heat treatment (Fig. 7a) are presented. EDS analysis shows that their chemical composition (in \% wt.) is as follows: Al64-79-Cu16-27-Fe3.3-6.4-Mn1.5-2.5 for the needlelike phases, and Al65-Mn15-Cu14-Fe6 for the irregular phases. The addition of nickel at a level of $0.5 \% \mathrm{wt}$. caused a change in the shape and chemical composition of those phases unaffected by heat treatment (see Fig. 7b). Their chemical composition (in \% wt.) amounts to Al42-52-Cu30-37-Ni17-20-Fe and Al64-Mn13-Cu15-Fe5.5-Ni2.5, respectively.

In the microstructure of alloy $\mathrm{F}(1.9 \% \mathrm{wt}$. $\mathrm{Ni}$ ), the coagulated phases can be seen. From the EDS analysis, the following phases can be distinguished: Al42-57-Cu24-34-Ni18-24, Al69-71-Ni21-23-Cu4.2-Fe2-2.5-Mn2-2.5, Al66-Mn21-Cu10-Ni2-Fe, and Al54-Cu21-Ni21-Mn2-Fe.

An EDS analysis shows that the interdendritic phases that were un-affected by heat treatment in alloy $\mathrm{F}$ contain a higher amount of copper as compared to base alloy A. This contributed to a reduction in the total content of copper dissolved in the $\alpha(\mathrm{Al})$ dendrites, a decrease in the number of strengthening particles, and an increase in their size (Fig. 7c, Fig. 8).

\subsection{Hardness measurements}

Figure 9 shows the results of Brinell hardness tests of the Al-Cu alloy in "as-cast" and T6 heat-treatment conditions as a function of nickel content.

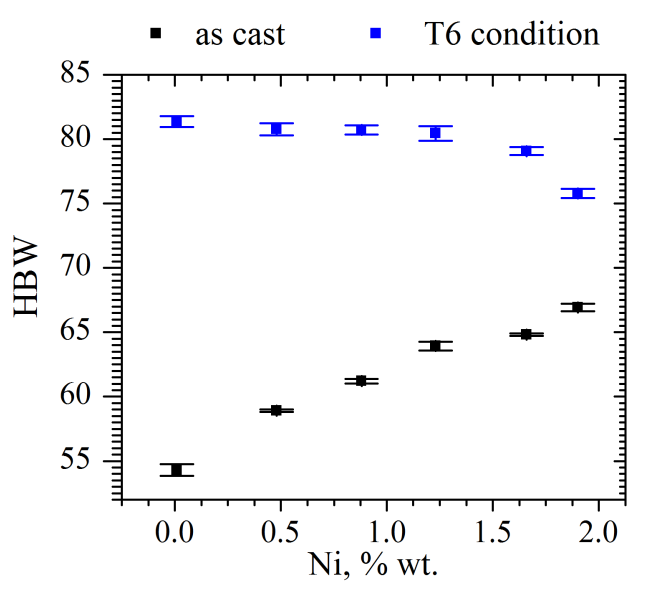

Fig. 9. The results of Brinell hardness of $\mathrm{Al}-\mathrm{Cu}-\mathrm{Mn}$ alloy as a function of nickel content

From Figure 9, it follows that hardness in the Al-Cu-Mn alloy increases (in "as-cast" condition) with the increased addition of nickel. The hardness of the investigated alloys increases almost linearly from a value of $54.3 \mathrm{HBW}$ (Alloy A) to a value of $66.9 \mathrm{HBW}$ at $1.9 \% \mathrm{wt}$. Ni (Alloy F). This strengthening effect is due to the higher percentage of hard phases (Fig. 6a) that are located in the interdendritic regions, whose hardness is much higher than the $\alpha(\mathrm{Al})$ phase.

As concerns heat-treated alloys, constant hardness is almost seen at a level of $81.5 \mathrm{HBW}$ up to a nickel content of $1.23 \%$ wt. For higher Ni content, a reduction in hardness to a value of $75.8 \mathrm{HBW}$ at $1.9 \% \mathrm{Ni}$ is observed. These changes are probably due to the lower density of the $\alpha(\mathrm{Al})$ phase, resulting from areduced copper content in the metallic matrix. Another factor that may affect hardness is less of a particle density, which are responsible for strengthening the metallic matrix.

According to the metallographic observations of alloys after heat treatment, an increase in the interdendritic phases fraction with increasing Ni content (Fig. 6a) can be seen. This complies with the tendency for an alloy that was not heat treated. Their growth undoubtedly contributes to a rise in the hardness of the alloy. According to the metallographic examinations (Fig. 8), the strengthening of the metallic matrix is the main factor (within the range of nickel content) that affects the final hardness of the examined $\mathrm{Al}-\mathrm{Cu}-\mathrm{Mn}$ alloys.

Due to the fact that hardness after T6 heat treatment is constant within the range of added nickel, it is likely that other strength parameters will not substantially deteriorate or even improve because of the more-favorable shape of those crystals undissolved during heat treatment, which is an indication that further investigations are necessary. 


\section{CONCLUSIONS}

This study investigated the effect of nickel on shaping the structure of the $\mathrm{Al}-5 \mathrm{Cu}-1 \mathrm{Mn}$ alloys in "as-cast" condition and after the T6 heat-treatment process. The present study allows us to draw the following conclusions:

1. Cooling curve analysis revealed the transformations associated with phases crystallization, whose transformations temperature (E1 and E4) depends on nickel content. The addition of nickel significantly lowers the transformation temperature of E4, which increases the crystallization temperature range of the tested alloys.

2 . The addition of nickel at a level of $0.5 \%$ changes the needle-like shape of the Al-Cu-Fe-Mn phases to blocky and coagulated. At this amount of nickel and its small solubility in aluminum, new interdendritic phases are not created. The growth conditions are affected by the incorporation of nickel atoms into the crystallographic structure, thereby changing the shape of the particles. Nickel substantially reduces the number of reinforcing particles in the metallic matrix and, simultaneously, increases their size.

3. According to the thermal analysis and EDS investigations, an addition of nickel at a level of $0.88 \%$ results in the formation in $\mathrm{Al}-5 \mathrm{Cu}-1 \mathrm{Mn}$ alloy of four different phases with a higher copper content, the deficit of which causes a lower degree of strengthening of $\alpha(\mathrm{Al})$ solution. An EDS microanalysis showed the presence in $\mathrm{Al}-5 \mathrm{Cu}-1 \mathrm{Mn}$ alloy with an addition of $1.9 \% \mathrm{wt}$. Ni the following phases (\% wt.): Al42-57-Cu24-34-Ni18-24, Al69-71-i21-23-Cu4.2-Fe2-2.5-Mn2-2.5, Al66-Mn21-Cu10-Ni2-Fe and Al54-Cu21-Ni21-Mn2-Fe.

4. For nickel content of $1.23 \%$, the lower degree of strengthening of $\alpha(\mathrm{Al})$ is compensated by the presence of hard interdendritic phases. Above this value, a decrease in hardness of the alloy was observed, probably due to a reduction in $\alpha(\mathrm{Al})$ density as a result of lower copper content in the metallic matrix. Another factor that may affect the hardness is the lower number of large particles that strengthen the primary grains of the $\alpha(\mathrm{Al})$ dendrites, which is an indication that further investigations are necessary.

\section{REFERENCES}

[1] Elgallad E.M., Samuela F.H., Samuela A.M. \& Dotyc H.W. (2010). Machinability aspects of new Al-Cu alloys intended for automotive castings. Journal of Materials Processing Technology, 210(13), 1754-1766.

[2] Polmear I.J., Pons G., Barbaux Y., Octor H., Sanchez C., Morton A.J., Borbidge W.E. \& Rogers S. (1999). After concorde: evauation of creep resistant $\mathrm{Al}-\mathrm{Cu}-\mathrm{Mg}-\mathrm{Ag}$ alloys. Materials Science and Technology, 15(8), 861-868.
[3] Elgallad E., Samuel F., Samuel A. \& Doty H. (2009). Development of new $\mathrm{Al}-\mathrm{Cu}$ based alloys aimed at improving the machinability of automotive castings. International Journal of Metalcasting, 3(2), 29-41.

[4] Górny M. \& Sikora G. (2015). Effect of titanium addition and cooling rate on primary $\alpha(\mathrm{Al})$ grains and tensile properties of Al-Cu alloy. Journal of Materials Engineering and Performance, 24(3), 1150-1156. doi:10.1007/s11665-014-1380-2

[5] Eskin D., Du Q., Ruvalcaba D. \& Katgerman L. (2005). Experimental study of structure formation in binary $\mathrm{Al}-\mathrm{Cu}$ alloys at different cooling rates. Materials Science and Engineering A, 405(1-2), 1-10. doi:10.1016/j.msea.2005.05.105

[6] Grosselle F., Timelli G., Bonollo F., Tiziani A. \& Della Corte E. (2009). Correlation between microstructure and mechanical properties of Al-Si cast alloys. La Metallurgia Italiana, 6, 25-32.

[7] Monroe R. (2005). Porosity in castings. AFS Transactions, 113, 519-546. doi:10.1002/chin.200642218

[8] Pietrowski S. (2011). Crystallisation and microstructure of low-silicon silumins with alloy additions. Archives of Foundry Engineering, 11(3), 113-124.

[9] Sikora G. (2015). Wpływ miedzi na strukturę pierwotną i przemianę eutektyczną w stopach Al-Cu. Archives of Foundry Engineering, 15(spec. 4), 113-118.

[10] Szajnar J. (2002). Rozkład miedzi w kryształach kolumnowych w odlewach wykonywanych $w$ polu magnetycznym. Archives of Foundry Engineering, 2(6), 213-218.

[11] Djurdjevič M.B. \& Grzinčič M.A. (2012). The effect of major alloying elements on the size of secondary dendrite arm spacing in the As-Cast Al-Si-Cu alloys. Archives of Foundry Engineering, 12(1), 19-24. doi:10.2478/v10266-0120004-2

[12] McCartney D.G. (1989). Grain refining of aluminum and its alloys using inoculants. International Materials Reviews, 34(5), 247-260.

[13] Molina R., Amalberto P. \& Rosso M. (2011). Mechanical characterization of aluminium alloys for high temperature applications. Part 2: Al-Cu, Al-Mg alloys. Metallurgical Science and Technology, 29(2), 5-13.

[14] Kaufman J.G. \& Rooy E.L. (2004). Aluminum Alloy Castings: Properties, Processes, and Applications. ASM International.

[15] Zolotorevsky V.S., Belov N.A., Glazoff M.V. (2007). Casting Aluminum Alloys (1st ed.). Amsterdam: Elsevier.

[16] Rohatgi P.K. \& Prabhakar K.V. (1975). Wrought aluminum-nickel alloys for high strength-high conductivity applications. Metallurgical Transactions A, 6(5), 1003-1008. doi:10.1007/BF02661353

[17] Hatch J.E. (1984). Aluminum: Properties and Physical Metallurgy. ASM International.

[18] Mrówka-Nowotnik G. (2010). Examination of intermetallic phrases in AlCu4Ni2Mg2 aluminium alloy in T6 condition. Archives of Metallurgy and Materials, 55(2), 489-497.

[19] Mrówka-Nowotnik G., Wierzbińska M., Sieniawski J. \& Nowotnik A. (2015). Investigation of solidification process and microstructure examination of $\mathrm{AlCu} 4 \mathrm{Ni2} \mathrm{Mg} 2$ aluminium alloy. Advances in Manufacturing Science and Technology, 39(4), 61-69. doi:10.2478/amst-2015-0023

[20] Belov N.A., Eskin D.G. \& Avxentieva N.N. (2005). Constituent phase diagrams of the $\mathrm{Al}-\mathrm{Cu}-\mathrm{Fe}-\mathrm{Mg}-\mathrm{Ni}-\mathrm{Si}$ system and their application to the analysis of aluminium piston alloys. Acta Materialia, 53(17), 4709-4722. doi:10.1016/j.actamat.2005.07.003 